\title{
Ensino de Bioética:
}

\section{um desafio transdisciplinar*}

\section{Eliane Elisa de Souza e Azevêdo ${ }^{1}$}

AZEVÊDO, E. E. de Souza. The teaching of Bioethics: a transdisciplinary challenge. Interface - Comunicação, Saúde, Educação, v.2, n.2, 1998.

Due to the fact that Bioethics is an area of knowledge which encompasses several disciplines, and due to its rapid development in a short time, academic challenges have been produced. The teaching of Bioethics has become a new experience which has no definite didactic model.

It is clear that traditional teaching, which is based on a disciplinary concept, has not been efficient to allow a complete understanding of Bioethics. Bioethics deals with knowledge in the cross-roads of several disciplines, suggesting a transdisciplinary concept for its teaching. Bioethics philosophical foundation, as those developed in European countries, strengthens its transdisciplinary dimension and recognizes anthropology (cultural and philosophical), as the theoretical support for its teaching. Thus, considering that Brazilian and European cultural and moral values are relatively similar, the European concept of Bioethics seems to be more adequate to support the teaching of Bioethics in Brazil.

KEY WORDS: Bioethics; education; teaching; anthropology.

O fato inovador de a Bioética ser uma área de conhecimento englobando várias disciplinas, e seu grande desenvolvimento em curto tempo, estão trazendo desafios de ordem acadêmica. O ensino da Bioética tornou-se uma nova experiência sem modelo didático definitivo. A forma tradicional de ensino baseada na concepção disciplinar não é eficaz para a completa compreensão desta nova área. A Bioética lida com saberes na encruzilhada de várias disciplinas, sugerindo uma concepção interdisciplinar ou mesmo transdisciplinar para seu ensino. A concepção filosófica da Bioética, conforme desenvolvida em países europeus, fortalece sua dimensão transdisciplinar e reconhece, na antropologia (cultural e filosófica), o suporte teórico para seu ensino. Assim, considerando a proximidade das culturas e valores morais das sociedades brasileira e européia, a concepção européia da Bioética parece mais apropriada para seu ensino neste país.

PALAVRAS-CHAVE: Bioética; educação; ensino; antropologia.

\footnotetext{
* Texto parcialmente apresentado no $2^{\circ}$ Seminário de Bioética, UNESP, Botucatu, 10-12 de setembro de 1997.

${ }^{1}$ Médica, PhD em Genética, Pesquisadora do CNPq, Coordenadora do Núcleo de Pesquisa e Educação Transdisciplinar em Bioética, Universidade Estadual de Feira de Santana, Bahia.
} 


\title{
Por que ensinar Bioética?
}

\author{
“... a perspectiva européia tende a compreender \\ a Bioética como uma nova disciplina filosófica de \\ dimensão transdisciplinar, a expressão \\ de uma nova sabedoria”. \\ M.C. Patrão Neves
}

Os novos conhecimentos sobre a vida e a natureza estão gerando técnicas com arrojado poder de manipulação do ser humano. O crescente uso destas técnicas estão revelando o descompasso entre o progresso da tecnologia $e$ a maturidade das reflexões morais sobre suas conseqüências. A maior evidência deste descompasso é o próprio surgimento da Bioética em 1971, seu rápido desenvolvimento, e o reconhecimento da necessidade de ensiná-la nas universidades, ao lado do ensino de ciências e sua aplicação (Clotet, 1993).

Idéias, reflexões $e$ análises que ofereçam padrões do que é bom e do que é ruim, do que é certo e do que é errado, à luz dos valores morais vigentes, estão se tornando parte integrante da formação profissional nas áreas da biologia, saúde, ambiente, direito, economia e comunicação, entre outras. A partir deste final de século, já se percebe que médicos, biólogos, enfermeiros, ecologistas etc., somente estarão preparados para o exercício profissional se, ao lado de competente formação técnica, também tiverem sido treinados para o reconhecimento de conflitos éticos, análise crítica de suas implicações, uso de senso de responsabilidade e obrigação moral ao tomar decisões relacionadas à vida humana.

A exigência deste tipo de profissional surge, não como inovação do academicismo teórico, mas como reivindicação das sociedades modernas e pluralistas (Pellegrino, 1990). O crescente número de cursos de Bioética em universidades americanas, latino-americanas, canadenses, australianas, européias e também brasileiras, estão propiciando não apenas ensino da Bioética em nível de graduação, aperfeiçoamento e especialização, mas, também, em algumas delas, a oferta de formação acadêmica específica com titulação em mestre e/ou doutor em Bioética.

Ainda que, em países do primeiro mundo, o ensino da Bioética esteja voltado, principalmente, para problemas éticos gerados pela aplicação de novas 
tecnologias, no Brasil, os problema bioéticos têm maior amplitude. A diversidade social, econômica e ambiental prevalente no país faz com que, ao lado dos problemas advindos dos avanços tecnológicos, persistam problemas nacionais específicos. A depender da unidade de ensino (saúde, medicina, biologia, filosofia, direito, etc), ou região do país em que se instalem cursos de Bioética, é importante que problemas brasileiros (Marques, 1996; Azevêdo, 1994), tanto quanto problemas pertinentes aos avanços da tecnologia, sejam analisados à luz de valores morais prevalentes na sociedade brasileira.

\section{Como ensinar Bioética?}

Sendo uma nova e complexa área de saber, com história tão recente que nem sequer completou quatro décadas, e com rapidez de crescimento sem precedentes na história das ciências, a Bioética, vive, na atualidade questionamentos fundamentais sobre seu próprio significado. É a Bioética uma disciplina? (Lenoir, 1996, p.68) Um movimento? Ou uma nova ciência a exigir métodos próprios para sua produção de conhecimento? (Bernard, 1994)

Aos poucos observa-se que a Bioética é mais que uma disciplina, é também mais que Ética Médica e talvez não seja apenas uma ética aplicada. Conseqüentemente, como ensinar Bioética, é o desafio pedagógico da atualidade.

Em seu artigo intitulado "Promover o Ensino da Bioética no Mundo" Lenoir (1996) alerta: "Se o escopo da Bioética deve ser multidisciplinar, resta saber se é preferivel tê-la dentro de uma formação disciplinar clássica - com o educador encarregado, responsável por recorrer às competências de outros participantes, segundo as modalidades que ele pode definir - ou se deve constituir uma nova disciplina por inteiro. Nesta última hipótese se coloca o problema da concepção da formação a ser usada pelos futuros professores de Bioética”. (p.68-69)

A magnitude do desafio exige reflexões sobre dois aspectos essenciais, discutidos a seguir: primeiro, a busca por uma concepção pedagógica que melhor responda às exigências da Bioética; segundo: a compreensão dos fundamentos filosóficos da Bioética tanto nos países anglo-americanos como europeus. 


\section{Bases conceituais e pedagógicas do ensino da Bioética}

A Bioética, à semelhança da Genética, desenvolveu-se em contexto caracterizado pela confluência de saberes de várias disciplinas e em plena era da ciência moderna. Estas semelhanças facilitam a percepção da transdisciplinaridade que permeia o conteúdo de conhecimento científico tanto em Genética como em Bioética, e voltarão à discussão adiante, no presente texto.

Ainda que a divisão do conhecimento em disciplinas seja arbitrário ( o objeto da ciência é a natureza que em si é única e indivisível), cientistas e educadores foram no passado, e continuam no presente, herdeiros de uma cultura que identifica as disciplinas como algo inerente ao conhecimento científico. Conseqüentemente, os saberes existentes na interface das disciplinas, apresentam difícil consolidação por pertencerem a áreas, supostamente, diferentes (Jacobi, 1997; Bruhn, 1995; Huff and Garrola, 1995; Azevêdo, 1997). Assim, surgiram termos e conceitos que, na encruzilhada das disciplinas, procuram sistematizar suas imbricações. Para Felice, Giordon e Souchon (1985) os termos multidisciplinaridade, interdisciplinaridade e transdisciplinaridade devem ser entendidos do seguinte modo:

\footnotetext{
Multidisciplinaridade ou pluridisciplinaridade - Consiste na simples justaposição de disciplinas. Nenhum pressuposto de ligação entre elas é exigido.

Interdisciplinaridade - requer o conhecimento do conceito de cada disciplina envolvida a fim de integrá-las.

Transdisciplinaridade - Requer uma unidade conceitual entre as disciplinas.
}

Na elaboração geral de cursos e currículos, a multidisciplinaridade é a forma mais simples e freqüentemente usada em qualquer parte do mundo.

A interdisciplinaridade, por sua vez, é um pouco mais difícil, porém é a marca de certas áreas do saber como a biologia, química, geologia, física, etc.

A transdisciplinaridade é considerada extremamente difícil de ser alcançada devido à ausência de conhecimentos profundos em mais de uma disciplina prevista para integração. É oportuno acentuar que toda esta dificuldade decorre, exatamente, da tradição histórica de produzir e transmitir conhecimento em pacotes chamados disciplinas os quais descaracterizam a unidade existente na ciência. 
2 Documento intitulado "Graduate and PostDoctoral Programs in Bioethics and Medical Humanities" apresenta ampla relação de cursos com as respectivas ementas e pode ser encontrado na internet no seguinte "site": <http:// www.med.upenn.edu/ bioethic/outreach/ bioforbegin/grad_ programs.html>

\footnotetext{
3 Sob o título

"Models for

Curriculum

Integration"

encontra-se

documento de dez

páginas e um elenco

de quarenta e sete

referências

bibliográficas sobre interdisciplinaridade, no seguinte "site": <http://www. Hellgate.k12.mt.us/ tp/cimodel.txt>
}

Hoje, perceber que para ser bioeticista é preciso também ser biólogo, médico, filósofo e jurista, nada mais é que repetir observação feita por Herbert Muller em 1922 em relação à Genética: "Devemos nós geneticistas sermos também bacteriologistas, fisiologistas químicos e físicos sendo simultaneamente zoólogos e botânicos?" A resposta foi dada pelo próprio Muller neste mesmo trabalho (Muller, 1922) publicado no American Naturalist: "Espero que sim". E o tempo confirmou a intuição de Muller e a transdisciplinaridade da genética

A diferença pedagógica entre o que ocorreu na Genética, no princípio deste século, e o que ocorre hoje com a Bioética, é que o reconhecimento da transdisciplinaridade em Genética foi privilégio subjetivo de poucos, enquanto em Bioética, a transdisciplinaridade já se constitui, em países europeus, uma proposta de concepção didática. (Patrão Neves, 1996; 1995)

Todavia, nas ementas de um elenco de quarenta e quatro cursos de Bioética, oferecidos em universidades norte-americanas, ${ }^{2}$ a maioria não define a concepção da disciplina, e em apenas cinco (11\%), o termo interdisciplinaridade é usado para definir a concepção didática do curso. Nesta mesma linha de pensamento existe quem admita ser a Bioética o protótipo do conhecimento interdisciplinar (Pasetti, 1995). Por outro lado, alguns educadores compreendendo a complexidade do ensino da Bioética, reconhecem a possibilidade de adiar-se a definição de uma concepção didática, neste estágio, contanto que o objetivo do ensino cumpra sua finalidade de "fazer com que os alunos tenham a capacidade de articular as diferentes visões disciplinares" (Lenoir, 1996).

Avaliando o cenário atual do ensino da Bioética, percebe-se que países europeus direcionam-se no sentido da transdisciplinaridade, enquanto as universidades americanas tendem à interdisciplinaridade ${ }^{3}$. Sendo a interdisciplinaridade um meio caminho à transdisciplinaridade, à medida que o tempo consolida as experiências pedagógicas em várias partes do mundo, a Bioética terá mais bem compreendida sua concepção didática.

\section{O desafio}

A Bioética é, reconhecidamente, um saber que exige práticas pedagógicas específicas. A diversidade de saberes que constitui a Bioética e seu objetivo didático de abrir horizontes para a percepção de responsabilidades morais, 
traduzem sua complexidade. Atingir este objetivo será extremamente difícil pela transmissão de conhecimentos de forma compartimentada, ministrados por professores, muitas vezes, sem compromisso acadêmico com a própria finalidade de ensinar Bioética. É fundamental que, pelo menos, um ou mais professores, diretamente responsáveis pelo ensino da Bioética, dominem o conceito de cada disciplina envolvida (interdisciplinaridade) ou melhor ainda, consiga, com esforço e tempo, perceber a unidade conceitual entre as disciplinas que compõem um curso de Bioética (transdisciplinaridade).

Finalmente, para o ensino da Bioética, percebe-se que uma concepção multidisciplinar não satisfará. A simples justaposição de conhecimentos de antropologia filosófica, biologia, genética, ética, filosofia e direito sem que os professores percebam a interdependência conceitual entre estas disciplinas, sua unidade conceitual e conheçam a especificidade de seus conteúdos, jamais resultará em ensino eficaz.

\section{Fundamentação filosófica da Bioética}

Comparando países europeus, de um lado, e anglo-americanos de outro, Patrão Neves $(1996 ; 1995)$ estudou o processo histórico de surgimento da bioética e os diversos fatores que moldaram seu desenvolvimento. A autora destaca a importância de se identificar uma fundamentação filosófica para a Bioética, relembrando que é a tradição filosófica de uma comunidade que molda sua mentalidade analítica e crítica (p.10). Com esta concepção, Patrão Neves identifica que nos países anglo-americanos a Bioética desenvolve-se em condições favoráveis à sua tecnicalização ou funcionalização já existindo, inclusive, a presença do profissional bioeticista nas instituições de saúde norteamericana. Também, nestes países, a tradição filosófica que fundamenta a bioética conduz ao desenvolvimento de normas, porque prevalece, nos países anglo-americanos, o entendimento que o "conjunto de regras que conduzam a uma boa ação, caracteriza uma moral" (p.11).

Nos países europeus continentais, ao contrário, prevalece a tendência de se compreender a Bioética como uma nova disciplina filosófica de dimensão transdisciplinar (Patrão Neves, 1996). Na Europa, a figura do bioeticista é substituída pela do consultor, e a tradição filosófica que fundamenta a bioética inquire "acerca do fundamento do agir humano, dos princípios que determinam a moralidade da ação, constituindo-se numa ética" (p.11). Estas diferenças decorrem exatamente de diferentes fatores que modelaram o desenvolvimento da Bioética nos países anglo-americanos, de um lado, e europeus do outro. 
${ }^{4}$ As referências aos trabalhos originais dos idealizadores dos diversos modelos são encontradas no trabalho de Patrão Neves, 1996.

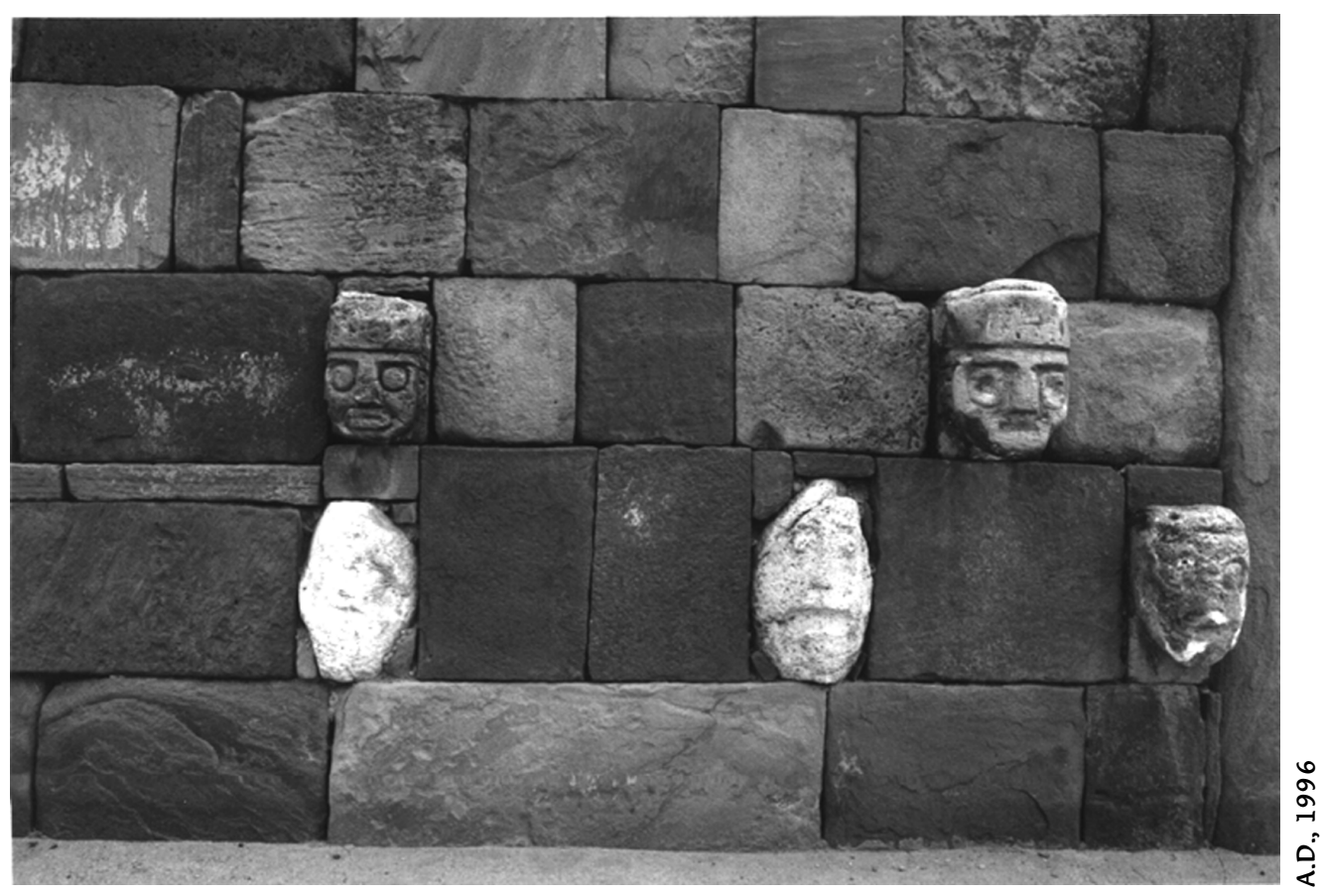

TIWANAKU, Bolívia.

Nos Estados Unidos, mais do que na Europa, existe, em uso, um elenco de modelos de análise teórica para fundamentação da bioética (Patrão Neves, 1996; 1995). Dentre estes, estão:

O modelo principialista (Beauchamp e Childress) ${ }^{4}$, que é o mais divulgado, no qual os princípios da beneficência, não-maleficência, justiça e autonomia são os norteadores das decisões. Muito bem recebido pela prática clínica, o modelo principialista tem suas raízes na história da filosofia ou na tradicional ética médica.

Além do modelo principialista existem também: - o modelo libertário (Engelhard) inspirado pelo liberalismo americano; - o modelo da virtude (Pellegrino e Thomasma) especialmente voltado para despertar nos profissionais da saúde o valor da virtude; - o modelo casuístico (Jonsen e Toulmin) o qual não se baseia em princípios e preconiza que cada caso seja analisado como um caso; - o modelo do cuidado (Gilligan) mais fundamentado na psicologia que na filosofia; o modelo contemporâneo ( Finnis) o qual estabelece que o conhecimento, a vida estética, a vida lúdica, a racionalidade prática, a religiosidade e a amizade são bens fundamentais em si mesmos; - o modelo contratualista (Veatch) fundamentado na importância de um tríplice contrato: entre médico-e-paciente, entre médico-esociedade e entre médico-e-princípios orientadores da relação médico-paciente. 
Nos países europeus, de modo geral, não existe boa aceitação para os modelos teóricos anglo-americanos. O que lá prevalece, segundo Patrão Neves, é um modelo europeu, denominado de personalista, o qual se desenvolveu com profundas raízes na filosofia européia contemporânea - fenomenologia, existencialismo e hermenêutica (Patrão Neves, 1996; 1995).

$O$ modelo personalista fundamenta-se na dignidade universal da pessoa como valor supremo, coloca a pessoa no centro das ações e decisões, e enuncia as categorias essenciais da pessoa como pessoa. Por ter a pessoa como centro, o modelo personalista busca, na fundamentação antropológica, um desenvolvimento harmonioso entre reflexão e prática. A pessoa torna-se o fundamento metafísico da ordem ética e a antropologia o fundamento da Bioética (Patrão Neves, 1996).

Desta forma, Patrão Neves estabelece que, para os países europeus, é na antropologia que se encontra a fundamentação filosófica da Bioética.

Entende-se, assim, que são os saberes em antropologia filosófica e também em antropologia cultural que constituem os pilares (referencial teórico) desta fundamentação. Percebe-se também que, para que se compreenda o valor da pessoa como fundamento metafísico da ordem ética, é necessário que se compreenda o que é a pessoa humana na plenitude de suas dimensões: dimensão cultural (linguagem, história, crenças, arte e ciência); dimensão metafísica ( transcendência, espiritualidade, morte, imortalidade); dimensão corpórea (funções, propriedades e valores do corpo humano), conhecimentos estes que constituem o conteúdo de livros didáticos em Antropologia Filosófica (Mondin, 1980; Cassirer, 1977; Groethuysen, 1982; Donceel, 1969; Vaz, 1993; Rabuske, 1986).

Além disto, sendo o ensino da Bioética direcionado a lidar com valores morais prevalentes em cada sociedade, e identificando o papel da cultura na modelagem destes valores, reconhece-se que conhecimentos da Antropologia Cultural de cada povo são indispensáveis ao preparo dos alunos, não só para compreensão da Bioética, mas, sobretudo, para melhor avaliar o impacto moral de suas ações $e$ decisões profissionais.

No caso específico do Brasil, cuja história cultural antropológica tem a peculiaridade de resultar da confluência de três culturas distintas (européia, africana e ameríndia), com implicações de diversidade de poderes sociais e econômicos em cada uma delas (Sousa, 1987; Azevêdo, 1983), será 
imprescindível ao aluno de Bioética conhecer a historia cultural de seu próprio povo. Somente o estudo das tradições de religiosidade, crenças, valores interpessoais e morais oriundos destas três culturas, e suas resultantes na contemporaneidade (após cinco séculos de convívio e miscigenação), darão ao aluno as ferramentas necessárias para auto-avaliar-se como produto da cultura brasileira, e, também, perceber o modo eficaz de interagir com a diversidade de pessoas neste país. Também aqui, livros de texto em Antropologia Cultural Brasileira apresentam conteúdo apropriado ao preparo do aluno em Bioética (Freyre, 1973; Sodré, 1977; Matta, 1981; Ribeiro, 1996).

\section{Conclusões}

Pelo fato de a Bioética ser uma área de saber complexa e recente, não existe, para seu ensino, uma tradição pedagógica específica nem uma experiência didática consolidada. A semelhança da Bioética com a Genética, na incorporação de conhecimentos de várias disciplinas para constituição do conteúdo específico de seu saber, retoma a reflexão feita por geneticistas no início deste século, na qual o conceito de transdisciplinaridade estava implícito.

Por outro lado, o forte impulso sob o qual se desenvolve a Bioética no mundo atual, reflete concepções filosóficas diferentes em países angloamericanos e em países europeus. Desta forma, é possível que formulações pedagógicas diferentes também prevaleçam nestes dois conjuntos de países, fundamentando o ensino da Bioética.

Considerando que a sociedade brasileira é mais herdeira de tradições, cultura $e$ valores morais de países europeus que anglo-americanos, espera-se que aqui predomine uma Bioética com fundamentação filosófica na antropologia e uma concepção pedagógica transdisciplinar para seu ensino.

\section{Referências bibliográficas}

AZEVÊDO, E. S. Sobrenomes no Nordeste e suas relações com a heterogeneidade étnica. Revista de Estudos Econômicos, v. 13, p. 103-116, 1983. Debate sobre Bioética deve abranger efeito da miséria. Folha de São

Paulo, 16 de out. 1994. Caderno Mais, p.6. 
AZEVÊDO, E. S. A Interdisciplinaridade na Ciência. O Modelo da Genética. Ciência e Cultura, Suplemento. São Paulo, v. 1, p. 113-115, 1997.

BERNARD, J. Da biologia à ética. Bioética. Os novos poderes da ciência. Os novos deveres do Homem. São Paulo: Ed. Promotora de Eventos, 1994.

BRUHN, J. G. Beyond disciplina: creating a culture for interdisciplinary research. Integrated Physiological Behavior Science v. 30, n.4, 331-341, 1995.

CASSIRER, E. Antropologia Filosófica. Ensaio sobre o Homem. Introdução a uma Filosofia da Cultura Humana. São Paulo: Mestre Jou, 1977.

CLOTET, J. Por que Bioética? Bioética, v. 1, n. 1, p. 13-19, 1993.

DONCEEL, J. F. Antropologia Filosófica. Buenos Aires: Ediciones Carlos Lohlé, 1996.

FELICE, J., GIORDAN, A , SOUCHON, C. Interdisciplinary approaches to environmental education. Environmental Education Series, n. 14. Paris. UNESCO - UNEP, 1985.

FREYRE, G. Problemas Brasileiros de Antropologia. 4. Ed. Rio de Janeiro: J. Olympio, 1973.

GROETHUYSEN, B. Antropologia Filosófica. Lisboa: Presença, 1982.

HUFF, F., GARROLA, G. Potencial patterns conceptual and pratical issues in interdisciplinary education. Journal of Allied Health v. 24, n. 4, p. 359-365, 1995.

JACOBI, P. Os Desafios da Interdisciplinaridade. A Experiência do PROCOM. Ciência e Cultura, Suplemento, v. 1, p. 118-121, 1997.

LENOIR, N. Promover o Ensino da Bioética no Mundo. Bioética, v. 4, n. 1, p. 6570, 1996.

MARQues, M. B. A Bioética na Política Pública do Brasil. Bioética, v. 4, n. 2, p. 145-158, 1996.

MATTA, R. Relativisando. Uma Introdução à Antropologia Social. 2. ed. Petropólis: Vozes, 1981.

MONDIN, B. O homem quem ele é? Elementos de Antropologia Filosófica. 2. ed. São Paulo: Paulinas, 1980.

MULLER, H. J. Variation due to change in the individual gene. The American Naturalist, v. 56, p. 32-50, 1922.

PASETTI, C. The teaching of bioethics to the health team: the neurologist role. Medicine and Law v. 14, n. 12, p. 87-91, 1995. 
PATRÃO NEVES, M. C. A Fundamentação Antropológica da Bioética. In: CONGRESSO DE BIOÉTICA DA AMÉRICA LATINA E CARIBE 1, 1995. São Paulo, Centro de Convenções, 1995.

A Fundamentação Antropológica da Bioética. Bioética, v. 4, n. 1, p. 7-16, 1996.

PELLEGRINO, E. D. La relación entre la autonomia y la integridad en la ética médica. Boletin de la Oficina Sanitaria Panamericana, v.108, n. 5 y 6, p. 379 390, 1990.

RABUSKE, E A . Antropologia Filosófica. Petropólis: Vozes, 1986.

RIBEIRO, D. O Povo Brasileiro. A Formação e o Sentido do Brasil. 2. ed. São Paulo: Companhia das Letras, 1996.

SODRÉ, N. W. Síntese da História da Cultura Brasileira. 5. ed. Rio de Janeiro: Civilização Brasileira, 1977.

SOUSA, M. G. F. , AZEVÊDO, E. S., SILVA, M.C.B. O, FREIRE, N.B.V.M. Brancos Descendentes de Negros na Sociedade Brasileira. Ciência e Cultura, v. 39, n.12, p. 1186-1189, 1987.

VAZ, H.C.L. Antropologia Filosófica I. 3. ed. São Paulo: Loyola, 1993. 


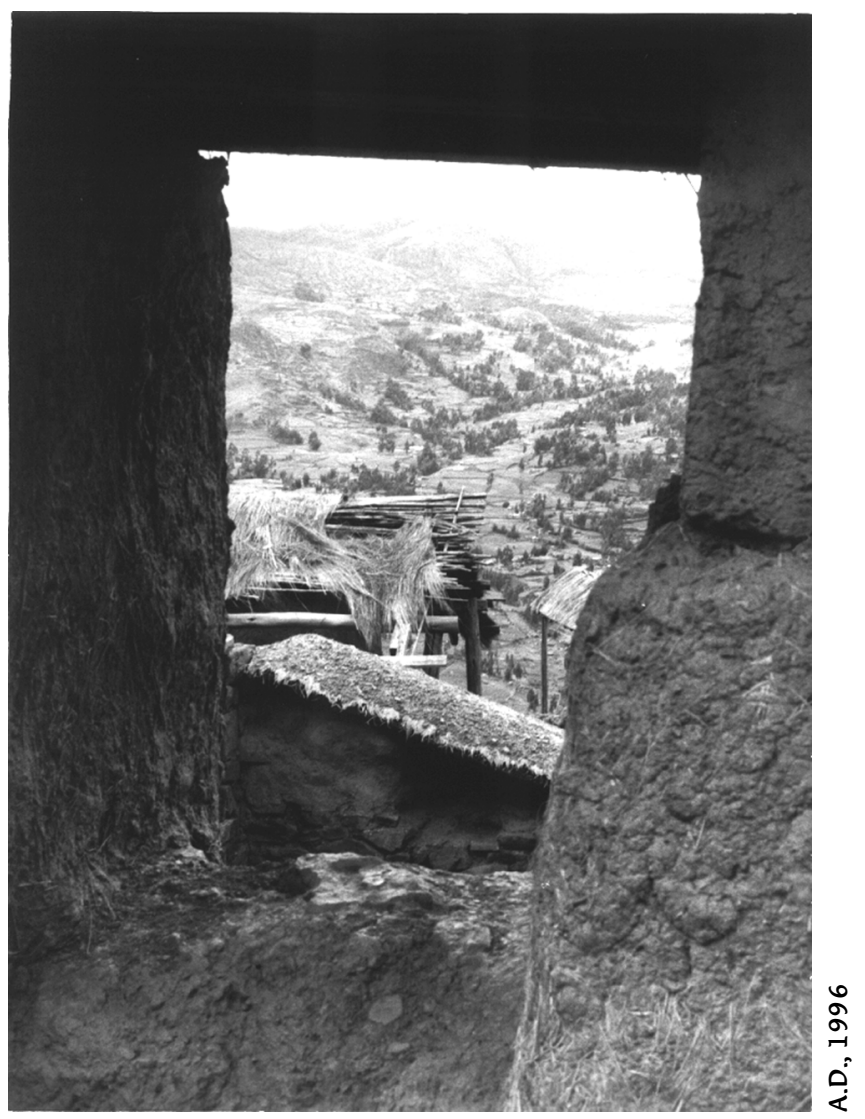

